\title{
Robust immune response stimulated by in situ injection of CpG/aOX40/cGAMP in aPD-1-resistant malignancy
}

\author{
Luya $\mathrm{Cai}^{1} \cdot$ Xuedan $\mathrm{Du}^{2}$. Cheng Zhang ${ }^{3}$. Shanshan $\mathrm{Yu}^{2} \cdot$ Lixiao Liu $^{1} \cdot$ Jinduo Zhao ${ }^{1} \cdot \mathrm{Ye} \mathrm{Zhao}^{1} \cdot$ Chunhong Zhang ${ }^{4}$.

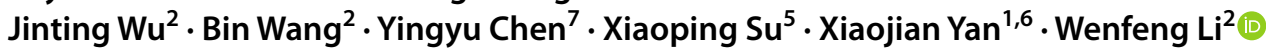

Received: 20 January 2021 / Accepted: 19 October 2021 / Published online: 3 November 2021

(c) The Author(s) 2021

\begin{abstract}
Recently, the emergence of immunotherapy has revolutionized traditional tumour treatment. However, effective treatments for patients exhibiting $\alpha \mathrm{PD}-1$ resistance are still lacking. In our study, a combination of cytosine-phosphate-guanine oligodeoxynucleotides (CpG-ODNs), anti-OX40 and cyclic guanosine monophosphate-adenosine monophosphate (cGAMP) injection in situ systematically generated a robust antitumour immune response in TC1 and B16 cells, which are $\alpha \mathrm{PD}-1$ resistant malignancies. More precisely, this method activates both adaptive and innate immunity. Additionally, in situ vaccination with $\mathrm{CpG} / \alpha \mathrm{OX} 40 / \mathrm{cGAMP}$ fully activates the production of cytokines. However, the combination of $\alpha \mathrm{PD}-1$ does not improve the efficacy of triple therapy, prompting further questions. Collectively, the combination of $\mathrm{CpG} / \alpha \mathrm{OX} 40 / \mathrm{cGAMP}$ causes the regression of various $\alpha \mathrm{PD}-1$-resistant tumours through the full mobilization of innate and adaptive immunity. In addition, we explored the therapeutic effect of triple therapy on the $\alpha \mathrm{PD}-1$-sensitive cell line CT26. The results showed that triple therapy could significantly enhance the therapeutic effect of $\alpha \mathrm{PD}-1$, and some mice even achieved complete tumour regression after the combined application of $\alpha \mathrm{PD}-1$ and triple treatment.
\end{abstract}

Luya Cai, Xuedan Du, Cheng Zhang and Shanshan Yu have contributed equally to this work

Xiaoping Su
bloooge@163.com
Xiaojian Yan
yxjbetter2016@hotmail.com
Wenfeng Li
lwf720325@126.com
Luya Cai
2047485876@qq.com
Xuedan Du
$786305503 @ q q . c o m$
Cheng Zhang
124895811@qq.com
Shanshan Yu
2326663980@qq.com
Lixiao Liu
568700647@qq.com
Jinduo Zhao
965456642@qq.com
Ye Zhao
wangxiaohua030@icloud.com
Chunhong Zhang
zch760217@163.com

Jinting Wu

1642370141@qq.com

Bin Wang

360597554@qq.com

Yingyu Chen

593244043@qq.com

1 Department of Obstetrics and Gynecology, The First Affiliated Hospital of Wenzhou Medical University, Wenzhou, Zhejiang, People's Republic of China

2 Department of Oncology, The First Affiliated Hospital of Wenzhou Medical University, Wenzhou, Zhejiang, People's Republic of China

3 Department of Dermatology, Taizhou Hospital of Zhejiang Province, Linhai, Zhejiang, China

4 Department of Pharmacy, The First Affiliated Hospital of Wenzhou Medical University, Wenzhou, Zhejiang, People's Republic of China

5 School of Basic Medical Science, Wenzhou Medical University, Wenzhou, Zhejiang, People's Republic of China

6 Center for Uterine Cancer Diagnosis and Therapy Research of Zhejiang Province, Women's Hospital and Institute of Translation Medicine, Zhejiang University School of Medicine, Hangzhou, China

7 Department of Neurosurgery, The First Affiliated Hospital of Wenzhou Medical University, Wenzhou, Zhejiang, People's Republic of China 
Keywords $\mathrm{CpG} / \alpha \mathrm{OX} 40 / \mathrm{cGAMP} \cdot \mathrm{In}$ situ vaccination $\cdot \alpha \mathrm{PD}$-1-resistant malignancies · Tumour immune microenvironment

\begin{tabular}{|c|c|}
\hline \multicolumn{2}{|c|}{ Abbreviations } \\
\hline CpG-ODN & $\begin{array}{l}\text { Cytosine-phosphate-guanine } \\
\text { oligodeoxynucleotides }\end{array}$ \\
\hline cGAMP & $\begin{array}{l}\text { Cyclic guanosine monophosphate-adenosine } \\
\text { monophosphate }\end{array}$ \\
\hline CTL & Cytotoxic T lymphocyte \\
\hline FBS & Foetal bovine serum. \\
\hline IDO & Indolamine-2,3-dioxygenase \\
\hline iNHL & Non-Hodgkin's lymphoma \\
\hline MF & Mycosis fungoides \\
\hline NSCLC & Non-small cell lung cancer \\
\hline
\end{tabular}

\section{Introduction}

The incidence and mortality rates of cancer are increasing gradually and are primary factors threatening human health. According to global cancer statistics, in 2018, approximately 18.1 million new cases of cancer were diagnosed worldwide, and approximately 9.6 million deaths occurred [1]. Currently, the traditional treatment methods for cancer include surgery, radiotherapy, chemotherapy and targeted therapy; however, each of these treatment methods has limitations, so the recurrence and metastasis of tumours remains a challenge, leading to a poor prognosis and low long-term survival rate in patients with advanced tumours. Therefore, studies exploring safer and more effective tumour treatment methods are urgently needed.

In recent years, the advent of immunotherapy has opened a novel chapter in the diversified treatment of various tumours, providing new hope for patients with cancer, particularly for some patients with advanced cancers. Currently, tumour immunotherapy is mainly divided into four categories according to the method: non-specific immune modulators, adoptive cell therapy, immune checkpoint inhibitors and tumour vaccines. Among them, the most common immunotherapy is PD-1/PD-L1 immune checkpoint inhibitors, which have been administered to many patients with cancer and have achieved a high response rate and lasting remission, significantly improving the survival rate of patients with recurrent or refractory Hodgkin's lymphoma [2-4], non-small cell lung cancer (NSCLC) [5-7], melanoma [8-10], etc., showing broad application prospects. Nevertheless, a large number of patients with cancer display a poor or ineffective response to PD-1/PD-L1 immune checkpoint inhibitors. Thus, an effective treatment must be developed for $\alpha$ PD-1-resistant patients.
In addition, in situ vaccination is a promising antitumour treatment method in which immune-enhancing agents are directly injected into the tumour site to stimulate the antitumour immune response throughout the body by inducing antigen release, promoting antigen presentation, activating immune effector cells, etc. [11]. A growing number of studies have focused on the antitumour efficacy of in situ vaccines. For example, Levy et al. found that the intratumour injection of low-dose cytosine-phosphate-guanine oligodeoxynucleotides (CpG-ODNs) induces the expression of $\mathrm{OX} 40$ on $\mathrm{CD}^{+}{ }^{+} \mathrm{T}$ cells, and the combination of $\mathrm{CpG}$ with agonistic anti-OX40 antibody further enhances the antitumour effect of immune cells, systematically shrinking the tumours in mice, particularly lymphoma [12]. Temizoz et al. found that intratumour injections of $\mathrm{CpG}$ and cGAMP effectively inhibited tumour growth in EG-7 and B16 F10 mouse tumour models [13]. According to Monjazeb et al., systemic blockade of the immunosuppressive enzyme indolamine2,3-dioxygenase (IDO) combined with $\mathrm{CpG} /$ radiotherapy in situ induces robust systemic antitumour effects [14]. Based on the excellent preclinical research results, a number of clinical trials were initiated. In patients with lowgrade B-cell lymphoma or mycosis fungoides (MF), systemic clinical responses to the combination of low-dose radiotherapy and $\mathrm{CpG}$ treatment have been observed in one tumour without serious treatment-related adverse events (NCT00185965, NCT00226993) [15, 16]. In patients with indolent non-Hodgkin's lymphomas (iNHLs), in situ vaccination with Flt3L, radiotherapy and a TLR3 agonist induced systemic clinical tumour regression (NCT01976585) [17]. However, researchers have not clearly determined whether in situ vaccines exert a therapeutic effect on tumours that do not respond to immune checkpoint inhibitors.

An extensive preliminary study and screening were performed to identify an in situ vaccine with good efficacy against $\alpha$ PD-1-resistant tumours. Notably, the combination of cyclic guanosine monophosphate-adenosine monophosphate (cGAMP), a STING agonist and $\mathrm{CpG} / \alpha \mathrm{OX} 40$ exerted a powerful vaccine effect; specifically, systemic tumour growth was significantly slowed, and surprising results were observed. In addition, in situ vaccination with $\mathrm{CpG} / \alpha \mathrm{OX} 40 /$ cGAMP increased the infiltration of immune cells in distant tumours and throughout the body, fully mobilized the production of cytokines and simultaneously activated adaptive and innate immunity (Fig. 1). Moreover, when we combined $\alpha \mathrm{PD}-1$ with $\mathrm{CpG} / \alpha \mathrm{OX} 40 / \mathrm{cGAMP}$, the antitumour effect was not enhanced but was instead inhibited to some extent. 


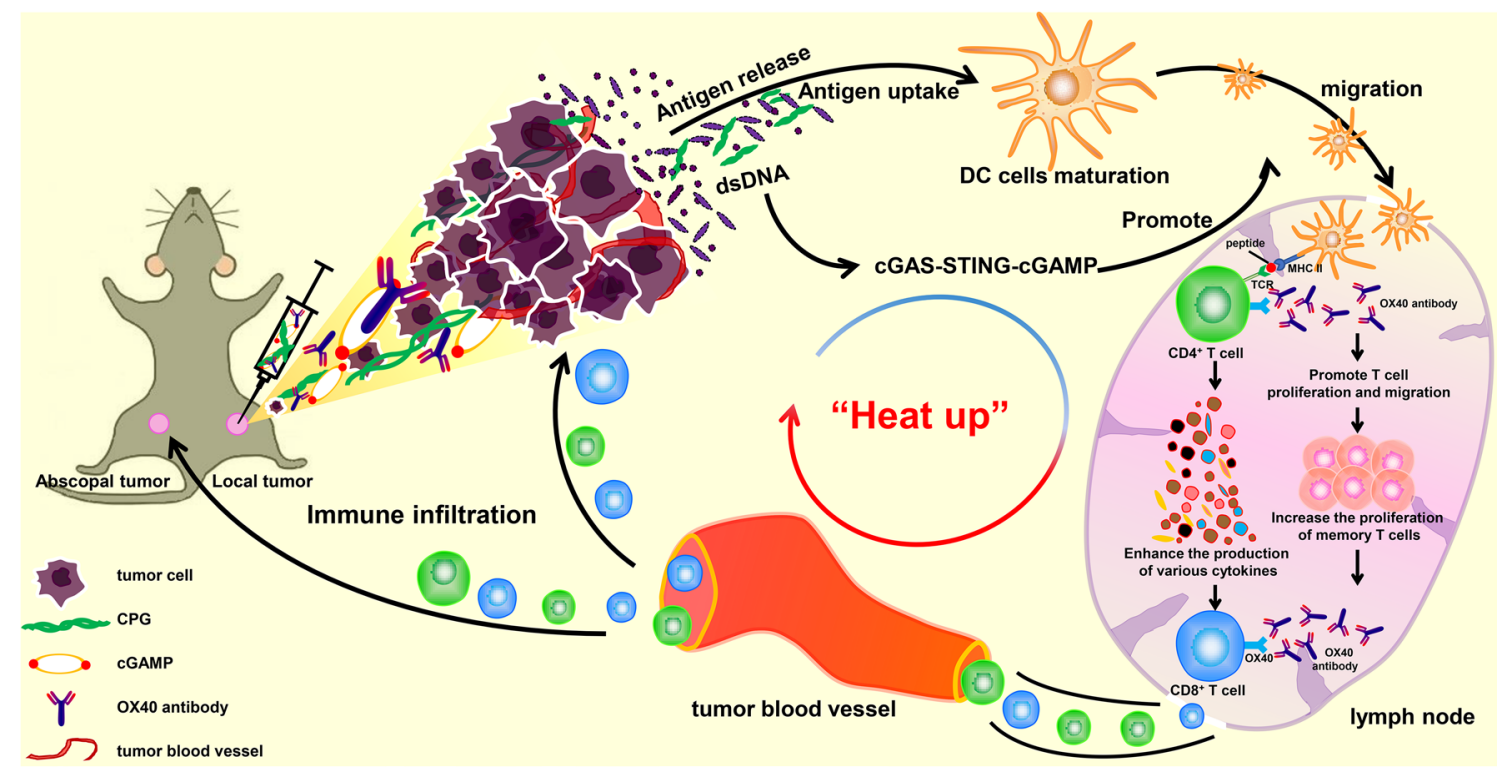

Fig. 1 Schematic diagram of the therapeutic mechanism by which triple therapy induces systemic antitumour effects

\section{Methods}

\section{Mice}

Female C57BL/6 mice and Balb/c mice (6-8 weeks old) were purchased from Hangzhou Ziyuan Experimental Animal Technology Co., Ltd. All mice were housed under specific pathogen-free conditions and maintained at a constant temperature $\left(22 \pm 1^{\circ} \mathrm{C}\right)$ and humidity $(60-70 \%)$. In addition, all animals were provided ultrapure water and clean food and housed on $12 \mathrm{~h}$ light/dark cycles. All animal experimental procedures were conducted in accordance with guidelines for the care and use of laboratory animals from the National Institutes of Health and were approved by the Animal Experimental Ethics Committee of Wenzhou Medical University.

\section{Cell lines and reagents}

The TC1, B16 and CT26 cell lines were purchased from the Cell Bank of Chinese Academy of Science (Shanghai, China). They were cultured in RPMI 1640 supplemented with $10 \%$ foetal bovine serum (FBS) (Sigma), $100 \mu \mathrm{g} / \mathrm{mL}$ penicillin and $100 \mu \mathrm{g} / \mathrm{mL}$ streptomycin in a humidified incubator at $37^{\circ} \mathrm{C}$ with $5 \% \mathrm{CO}_{2}$.

CpG-ODN 2395 was provided by Synbio Technologies (Suzhou, China). The agonistic anti-OX40 antibody was provided by BioXcell (West Lebanon, USA). 2'3'-cGAMP was purchased from InvivoGen (Cat.\# tlrl-nacga23m). CD4-, CD8- and NK-depleting antibodies were purchased from BioXcell (USA).

\section{Tumour inoculation and animal experiment}

For the construction of a mouse model for the $\alpha \mathrm{PD}-1$ treatment experiment, the left flank of each C57BL/6 mouse was subcutaneously injected with $2 \times 10^{5} \mathrm{TC} 1 / \mathrm{B} 16$ cells $(50 \mu \mathrm{L}$ of PBS) on day 0 . When the tumour volume reached 10-20 $\mathrm{mm}^{3}$ on day 6 or 7 , the mice were randomly divided into 2 groups: the PBS and $\alpha$ PD-1 groups. PBS or $\alpha$ PD-1 (100 $\mu \mathrm{g} /$ mouse) was administered by intraperitoneal injection every 2 days for 3 injections.

For the mouse model of systemic tumour, the left flank of each C57BL/6 mouse was subcutaneously injected with $2 \times 10^{5} \mathrm{TC} 1 / \mathrm{B} 16$ cells (50 $\mu \mathrm{L}$ of PBS) (primary tumour) on day 0 , and the same number of TC1/B16 cells was injected subcutaneously on the other side on day 2 . On day 7 , when the TC1 tumour volume reached $10-20 \mathrm{~mm}^{3}$, the mice were randomly divided into the following 5 groups: $\mathrm{PBS}, \mathrm{CpG}$, cGAMP, $\mathrm{CpG} / \alpha \mathrm{OX} 40$ and $\mathrm{CpG} / \alpha \mathrm{OX} 40 / \mathrm{cGAMP}$. $\mathrm{CpG}$ (50 $\mu \mathrm{g} /$ mouse), $\alpha \mathrm{OX} 40$ (30 $\mu \mathrm{g} / \mathrm{mouse})$ and cGAMP $(10 \mu \mathrm{g} /$ mouse) were administered by in situ injection only into the primary tumour every 2 days for 3 injections. When the B16 tumour volume reached $5-10 \mathrm{~mm}^{3}$, the treatment began.

For the cell depletion experiment, anti-CD4 (clone GK1.5, BioXCell), anti-CD8 (clone 2.43, BioXCell) or antiNK (clone PK136, BioXCell) mAbs were intraperitoneally injected at a dose of $200 \mu \mathrm{g} /$ mouse one day before therapy. When the treatment began, each mouse was injected with $100 \mu \mathrm{g}$ of the anti-CD4, anti-CD8 or anti-NK mAbs every 2 days for 5 injections. Finally, a flow cytometry analysis of blood samples was performed to validate whether $\mathrm{CD} 4^{+} \mathrm{T}$ cells, $\mathrm{CD} 8^{+} \mathrm{T}$ cells or NK cells were successfully knocked out. The tumour dimensions were measured with Vernier 
callipers every 2 or 3 days, and the tumour volume was calculated using the following equation: length $\times$ width $^{2} / 2$ $\left(\mathrm{mm}^{3}\right)$. Mice were killed when the tumour volume reached $1500 \mathrm{~mm}^{3}$.

To explore the efficacy of the triple drug in the PD1-sensitive cell line CT26, we subcutaneously injected $4 \times 10^{5} \mathrm{CT} 26$ cells into the left flank of Balb/C mice (primary tumour) and 2 days later injected the same number of CT26 cells into the right side (distant tumour). Mice were randomly divided into 4 groups - the PBS group, $\alpha$ PD- 1 group, $\mathrm{CpG} / \alpha \mathrm{OX} 40 / \mathrm{cGAMP}$ triple group and $\mathrm{CpG} / \alpha \mathrm{OX} 40 /$ cGAMP $/ \alpha$ PD-1 quadruple group - and treated on day 5 with the same drug dose as previously described. The tumour size and body weight of the mice were observed every $2-3$ days. The mice were killed when the tumour volume reached 1500 $\mathrm{mm}^{3}$.

\section{Flow cytometry analysis}

Mouse spleen tissues were completely ground in the filter and digested with a tumour dissociation kit (Miltenyi Biotec Inc.) at $37{ }^{\circ} \mathrm{C}$ for $1 \mathrm{~h}$, and the suspension was filtered through $40 \mu \mathrm{m}$ sieves to obtain a single-cell suspension. Next, the single-cell suspension was placed in $0.02 \%$ saline for approximately $20 \mathrm{~s}$ and then neutralized with an equal volume of $0.16 \%$ saline to lyse the erythrocytes. One hundred microlitres of the single-cell suspension $\left(\sim 10^{6}\right.$ cells $)$ was stained with CD45-APC-A750, CD3e-FITC, CD4-APC, CD8-PC7, CD3-APC, CD11c-FITC and MHC II-PE antibodies and incubated at $4{ }^{\circ} \mathrm{C}$ in the dark for $30 \mathrm{~min}$. After washing with staining buffer, a CyFLEX flow cytometer (Beckman Coulter) was used to conduct flow cytometry. The voltage was regulated by a negative control and single dye tube. The final data were analysed using CytExpert software.

\section{Cytokine assay}

Blood samples were collected from blood vessels into a tube without anticoagulant and centrifuged twice for $20 \mathrm{~min}$ $\left(4{ }^{\circ} \mathrm{C}, 3000 \mathrm{G}\right)$ after incubation at room temperature for $2 \mathrm{~h}$, and the supernatant was collected to analyse the changes in cytokine levels in the treated mice. The serum levels of Th1 (IL-2, IFN- $\gamma$ and TNF), Th2 (IL-4, IL-6 and IL-10) and Th17 (IL-17A) cytokines were detected using a CBA kit according to the manufacturer's instructions.

\section{Statistical analysis}

All statistical analyses were performed using GraphPad Prism 7.0 software and SPSS 16.0. All data are presented as means \pm SEM. Two-way ANOVA was used to examine the differences between groups, and $P<0.05$ was considered significant.

\section{Results}

\section{aPD-1 treatment did not produce a therapeutic benefit in mouse models of cervical cancer and melanoma}

Mice bearing TC1/B16 tumours were treated with $\alpha$ PD- 1 (100 $\mu \mathrm{g} /$ mouse) 3 times, but no difference in tumour volume was observed between the treatment group and the PBS group (Fig. 2a-b). Therefore, we concluded that these two types of cells are indeed $\alpha \mathrm{PD}-1$-resistant, consistent with previous studies [18-20]. We chose TC1/B16 cell lines for follow-up studies.
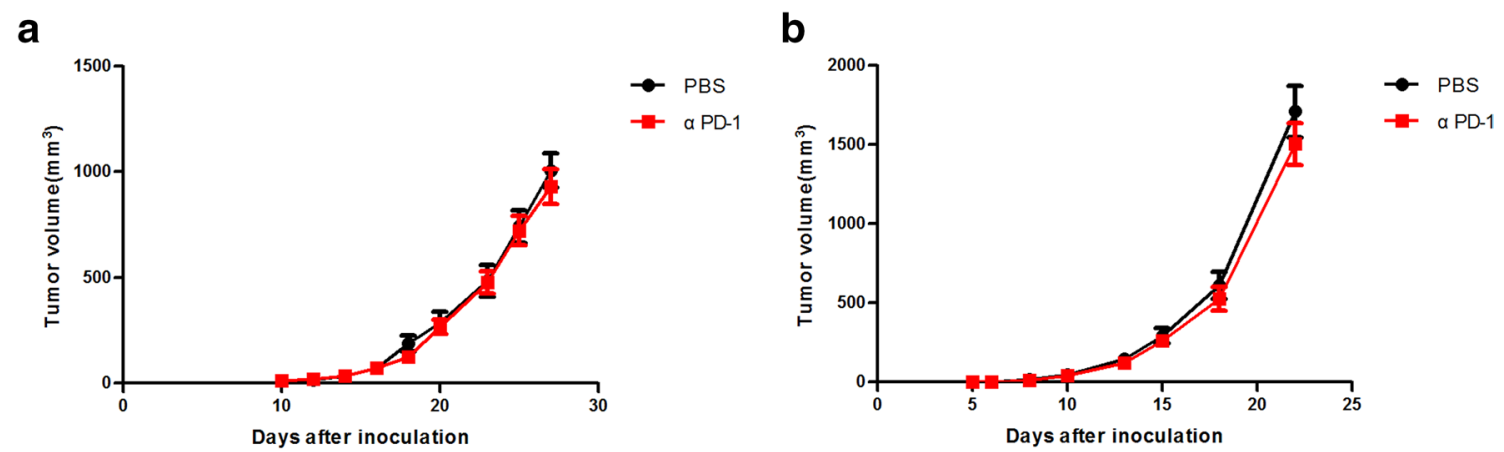

Fig. 2 TC1/B16 tumours do not respond to $\alpha$ PD-1 immune checkpoint inhibitors. a TC1 and b B16 
Fig. $3 \mathrm{CpG} / \alpha \mathrm{OX} 40 / \mathrm{cGAMP}$ therapy exerted a systemic antitumour effect on $\alpha$ PD-1resistant tumours. a Treatment flowchart for TC1 mouse models. C57BL/6 mice were subcutaneously injected with $2 \times 10^{5} \mathrm{TC} 1$ cells $(50 \mu \mathrm{L}$ of PBS) in the left flank (local tumour) on day 0 and in the right flank (distant tumour) on day 2. The treatment began on approximately day 7 , when the tumour volume reached 10-20 $\mathrm{mm}^{3}$. The TC1 tumour growth curves for the treated side (b) and untreated side (c) are shown. Pictures of TC1 tumours harvested from the treated side (d) and untreated side $\mathbf{e}$ of mice are shown. $\mathbf{f}$ Changes in the weight of TC1 tumour-bearing mice. B16 tumour growth curves for the treated side (g) and untreated side (h) are shown. CpG/ $\alpha$ OX40/cGAMP therapy significantly prolonged the survival time of TC1 (i) and B16 (j) tumour-bearing mice a

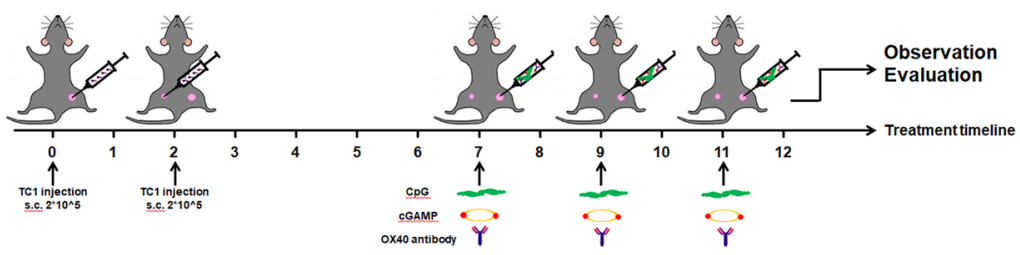

b

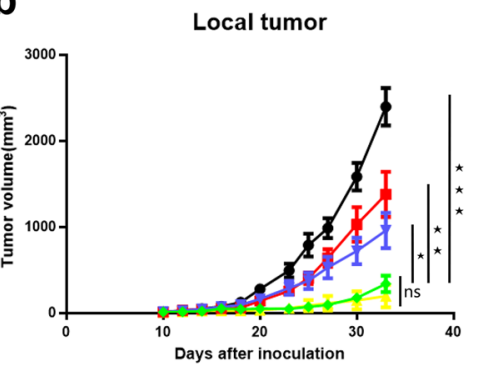

C

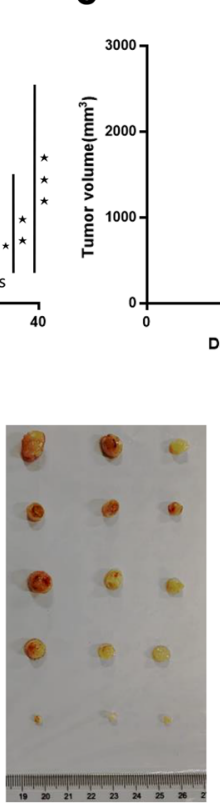

Distant tumor

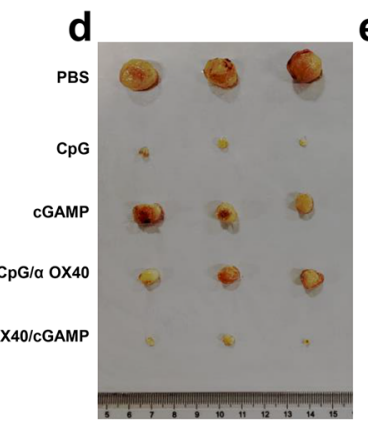

e

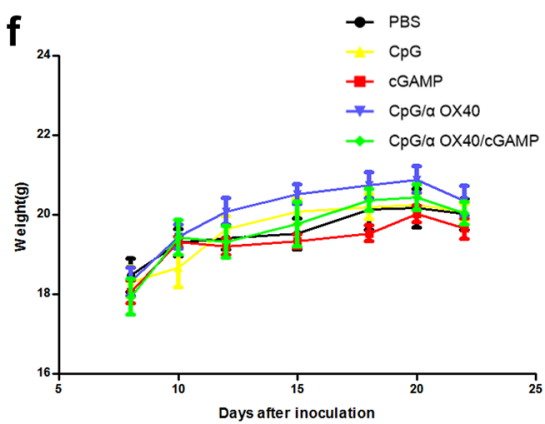

g

Local tumor

h

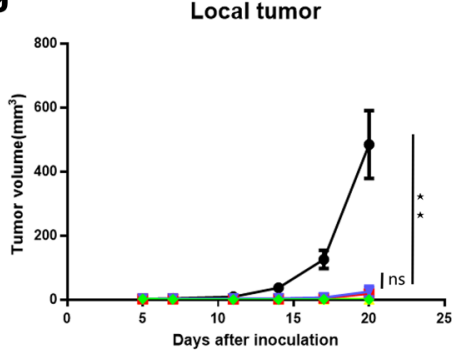

Distant tumor

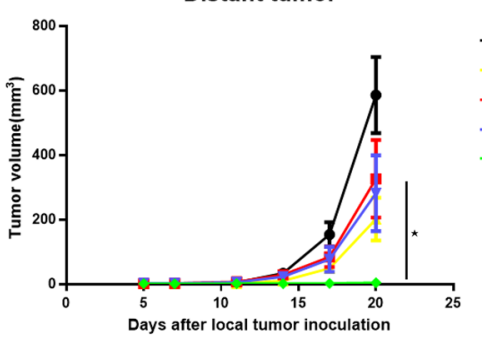

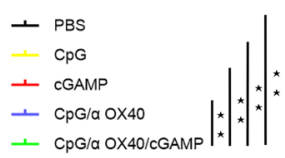

- PBS

CPG

- cGAMP

$\rightarrow$ CpG/a OX40

$\rightarrow$ Cpg/a OX40/cGamp i
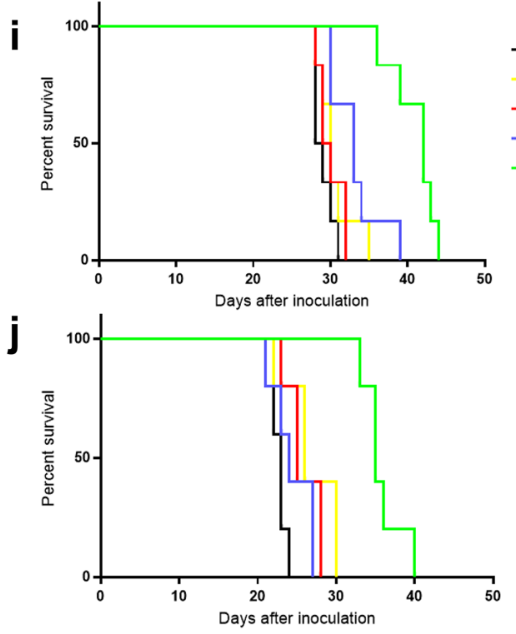

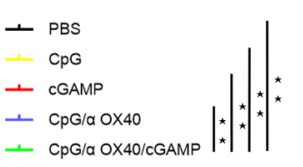




\section{CpG/aOX40/cGAMP exerted a systemic antitumour effect on aPD-1-resistant tumours}

A mouse model of $\alpha$ PD-1-resistant tumours was established, and all the treatments were only administered to the primary tumour to study the systemic efficacy of an in situ vaccine in $\alpha$ PD-1-resistant tumours (Fig. 3a). For mice bearing TC1 tumours, the growth rate of local tumours in the $\mathrm{CpG}$, cGAMP, $\mathrm{CpG} / \alpha \mathrm{OX} 40$ and $\mathrm{CpG} / \alpha \mathrm{OX} 40 / \mathrm{cGAMP}$ groups was significantly slower than that in the PBS group, particularly in the triple therapy group (Fig. 3b). However, when we observed distant tumours, the tumour growth rate of the other treatment groups was not slower, with the exception of the triple therapy group (Fig. 3c). In addition, we more intuitively observed an obvious difference in the tumour volume in each group from the photographs of tumours in mice (Fig. 3d-e). We concluded that the administration of this type of triple therapy to TC1 tumours significantly inhibited tumour growth and produced a systemic antitumour effect that was significantly stronger than the single-drug or $\mathrm{CpG} /$ $\alpha \mathrm{OX} 40$ therapy. In addition, no significant difference in body weight was detected among these five groups, and no weight loss occurred after treatment, indicating that triple therapy was safe (Fig. 3f). Similar results were obtained for mice bearing B16 tumours (Fig. 3g-h), and triple therapy was the most effective.

Furthermore, we evaluated the survival time of tumourbearing mice. The average survival time of TC1 tumourbearing mice in the control group, namely the PBS group, was less than 30 days, while the survival time of mice treated with triple therapy was significantly prolonged to more than 40 days, with $P<0.01$. The survival time of mice in the other treatment groups was not significantly different from that of the PBS group (Fig. 3i). Triple therapy also significantly prolonged the survival time of B16 tumour-bearing mice (Fig. 3j).

\section{The efficacy of triple therapy in modulating adaptive immunity in mice}

We analysed the changes in T cells and DCs in mice to explore the effect of triple therapy on adaptive immunity. Using flow cytometry, we found that the proportions of $\mathrm{CD}^{+}, \mathrm{CD}^{+}$and $\mathrm{CD}^{+} \mathrm{T}$ cells in the spleens of the triple therapy group of mice were noticeably increased, and the proportion of $\mathrm{T}$ cells was approximately twice as high as that in the PBS group (Fig. 4a). In the other treatment groups, although $\mathrm{T}$ cells were also increased to varying degrees, the changes were not as obvious as in the triple therapy group (Fig. 4a). Regarding the intratumoural $\mathrm{T}$ cells in the untreated tumours, interesting phenomena were observed. When the mice were treated with $\mathrm{CpG} / \alpha \mathrm{OX} 40$ therapy, the proportions of both $\mathrm{CD}^{+}$and $\mathrm{CD}^{+} \mathrm{T}$ cells were remarkably increased compared to those in the PBS, $\mathrm{CpG}$ and cGAMP groups, which was consistent with previous studies. However, in the $\mathrm{CpG} / \alpha \mathrm{OX} 40 / \mathrm{cGAMP}$ group, the proportion of $\mathrm{CD}^{+} \mathrm{T}$ cells was also strikingly increased and was the highest among all treatment groups, but the proportion of $\mathrm{CD}^{+} \mathrm{T}$ cells showed a slight decreasing trend, and the proportion of $\mathrm{CD}^{+} \mathrm{T}$ cells was substantially increased from 25 to $60 \%$ (Fig. 4a). In addition, we also detected changes in DC cells in the spleens of mice. From the results, we can see that although $\mathrm{CpG}$ alone can induce the maturation of DCs, its effect was not ideal and lasting. When combined with $\alpha \mathrm{OX} 40$ and cGAMP, the proliferation of DCs was the most significant (Fig. 4b-c).

\section{The antitumour effect of triple therapy depends on the full mobilization of adaptive immunity and innate immunity}

We conducted a cell depletion experiment to verify the importance of adaptive immunity and further explore the role of innate immunity in the effects of triple therapy. First, we used antibodies to knock out a certain cell type in mice, including $\mathrm{CD}^{+}{ }^{+} \mathrm{T}$ cells, $\mathrm{CD}^{+} \mathrm{T}$ cells and NK cells (Supplementary Fig. 1). Regardless of what cell type was knocked out, triple therapy still exerted a strong antitumour effect on the treated side of the tumours, and no difference in the tumour volume was observed compared with the triple therapy group without antibody knockout (Fig. 5a). On the untreated side, although triple therapy still exerted a certain effect when $\mathrm{CD}^{+}{ }^{+} \mathrm{T}$ cells, $\mathrm{CD} 8^{+} \mathrm{T}$ cells or $\mathrm{NK}$ cells were knocked out, the curative effect was significantly reduced (Fig. 5b). Thus, we speculated that in addition to adaptive immunity, innate immunity is also essential for mediating the effects of triple therapy. Next, we conducted a joint knockout experiment in mice. When we knocked out both $\mathrm{CD}^{+}{ }^{+}$and $\mathrm{CD}^{+} \mathrm{T}$ cells, the efficacy of triple therapy was still strong; although the treated tumours tended to grow, the difference was not obvious. Triple therapy was still effective against untreated tumours (Fig. 5c). The systemic antitumour effect of the triple therapy disappeared only when $\mathrm{CD}^{+}, \mathrm{CD}^{+} \mathrm{T}$ cells and NK cells were knocked out, and the distant tumour grew rapidly and even tended to surpass that in the control group (Fig. 5d). Thus, adaptive immunity and innate immunity play essential roles in antitumour immunity.

\section{Triple therapy systematically affects cytokine production in mice}

In addition to immune cells, cytokines also play a crucial role in antitumour therapy. Thus, serum cytokine levels in mice after treatment were measured using CBA kits. After the different treatments, the levels of Th1 (IL-2, IFN- $\gamma$ and TNF), Th2 (IL-4, IL-6 and IL-10) and Th17 (IL-17A) 
a
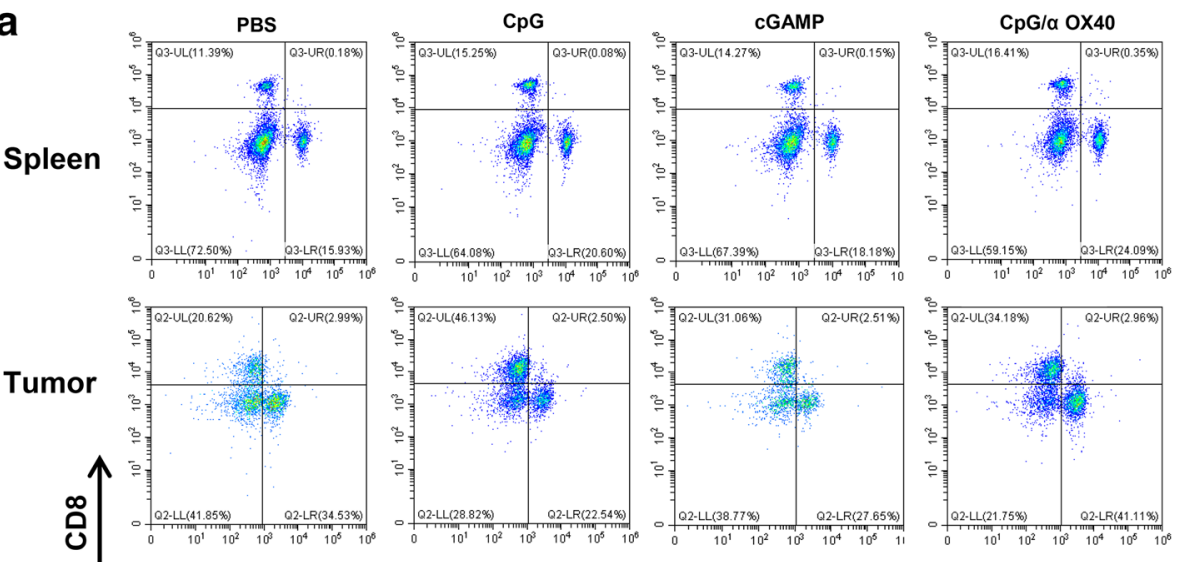

Tumor
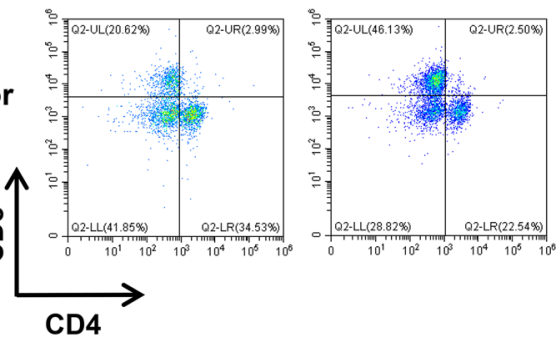
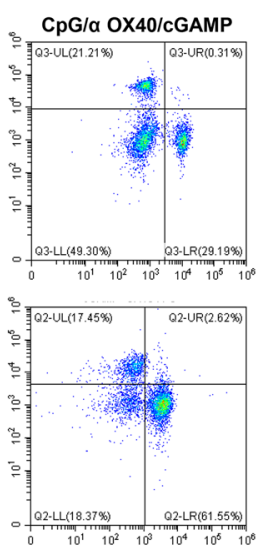

Gated on CD45+ cells

b
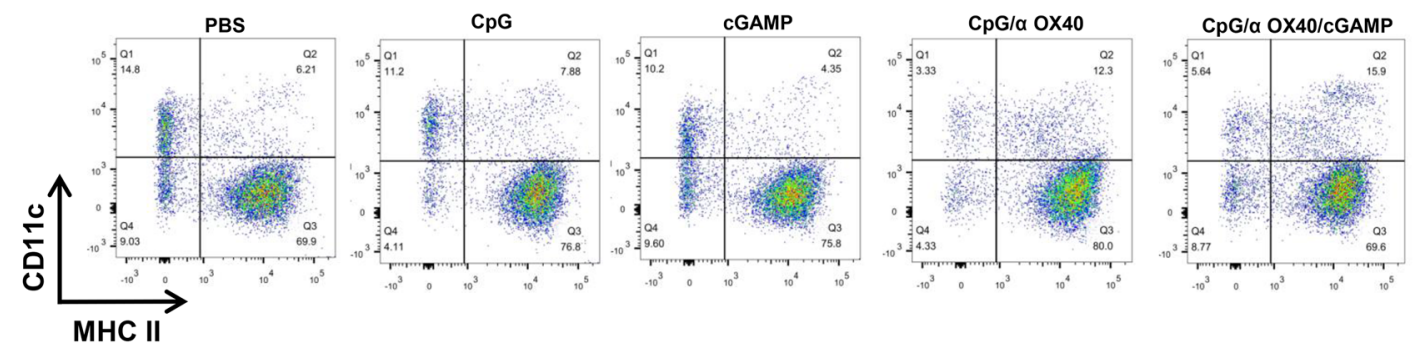

Gated on CD45+ CD3- cells

C

8 days after drug injection

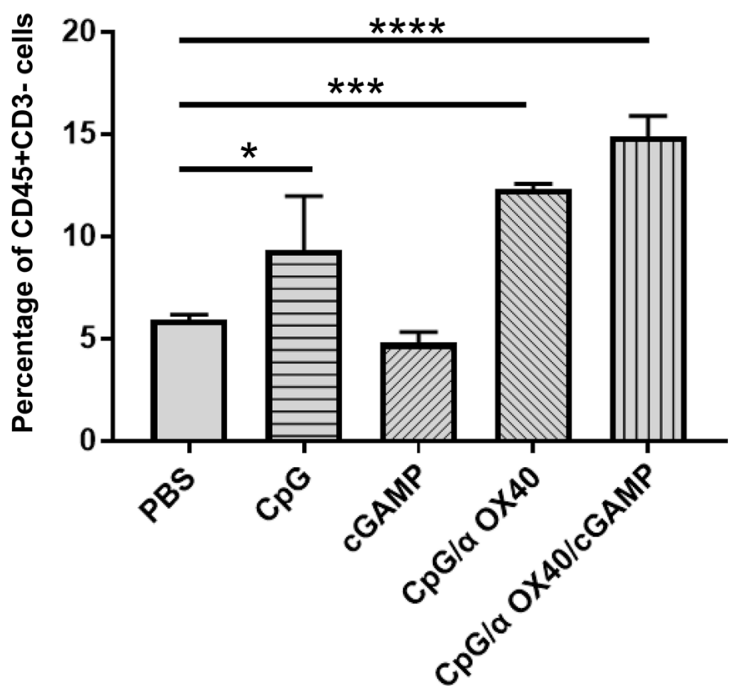

14 days after drug injection

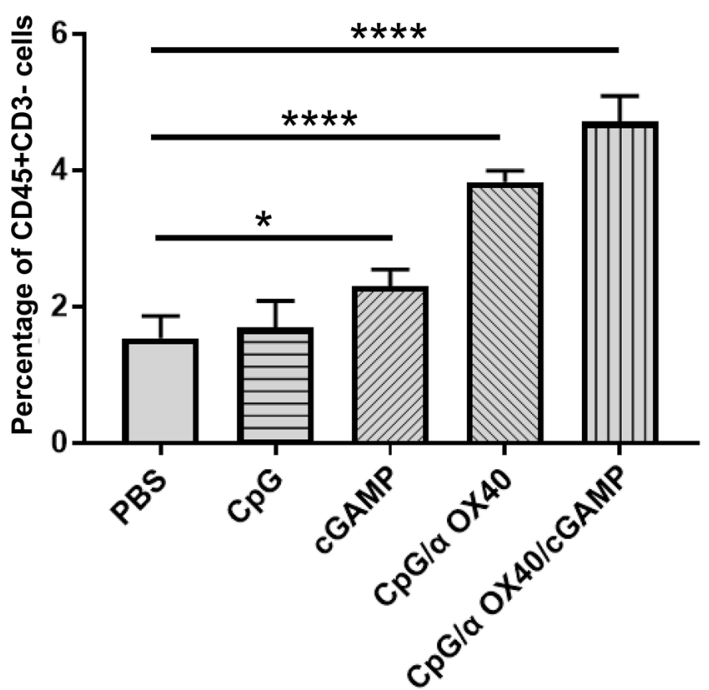

DC content among groups on the 8th (left) and 14th (right) days after treatment (the bar graphs represent the quantitative analysis of three independent experiments)

triple therapy, various cytokines are fully mobilized to exert a powerful antitumour effect. triple therapy group, including both immunostimulatory cytokines and immunosuppressive cytokines (Fig. 6). After 

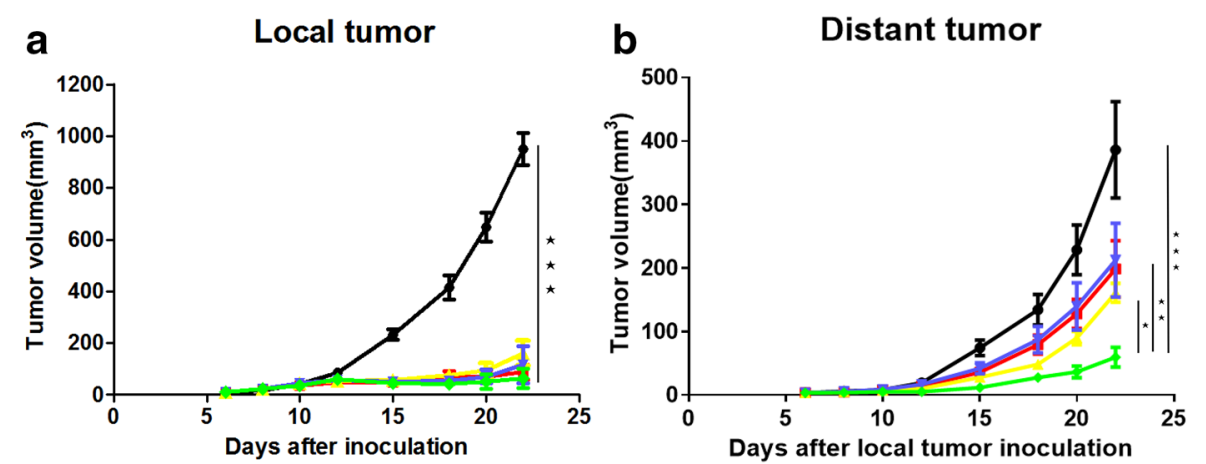

$\rightarrow$ PBS

$\rightarrow$ Triple $+\alpha$ CD4

- Triple+a CD8

- Triple+a NK

$\rightarrow$ Triple therapy
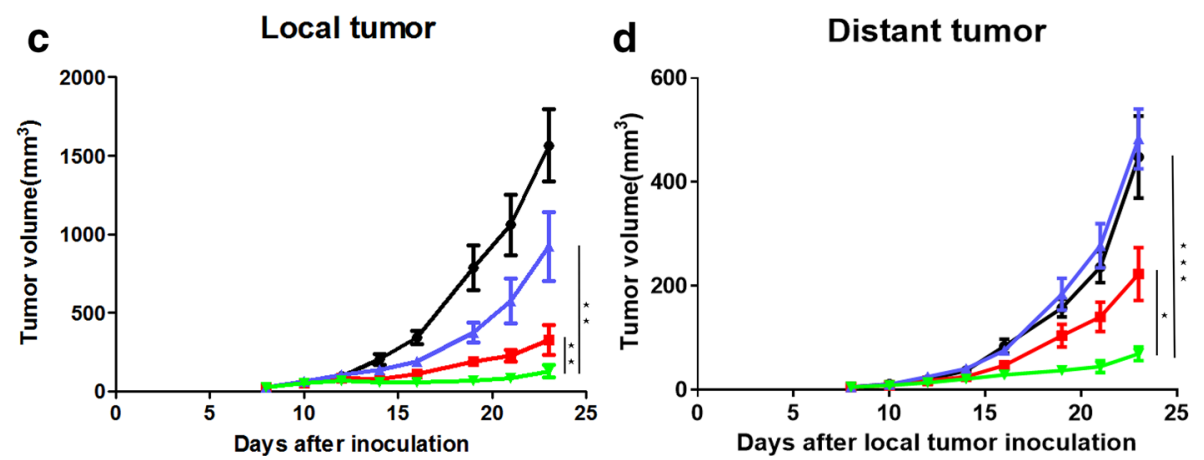

$\rightarrow$ PBS

$\rightarrow$ Triple $+\alpha$ CD4/CD8

- Triple+a CD4/CD8/NK

- Triple therapy

Fig. 5 The antitumour effect of triple therapy depends on the full mobilization of adaptive immunity and innate immunity. TC1 tumour growth curves for the treated side (a) and untreated side (b) when $\mathrm{CD}^{+} \mathrm{T}$ cells, $\mathrm{CD}^{+} \mathrm{T}$ cells or NK cells were knocked out are shown.
The TC1 tumour growth curves for the treated side (c) and untreated side (d) when both $\mathrm{CD} 4^{+} \mathrm{T}$ cells and $\mathrm{CD} 8^{+} \mathrm{T}$ cells or all $\mathrm{CD} 4^{+} \mathrm{T}$ cells, $\mathrm{CD}^{+} \mathrm{T}$ cells and NK cells were knocked out are shown
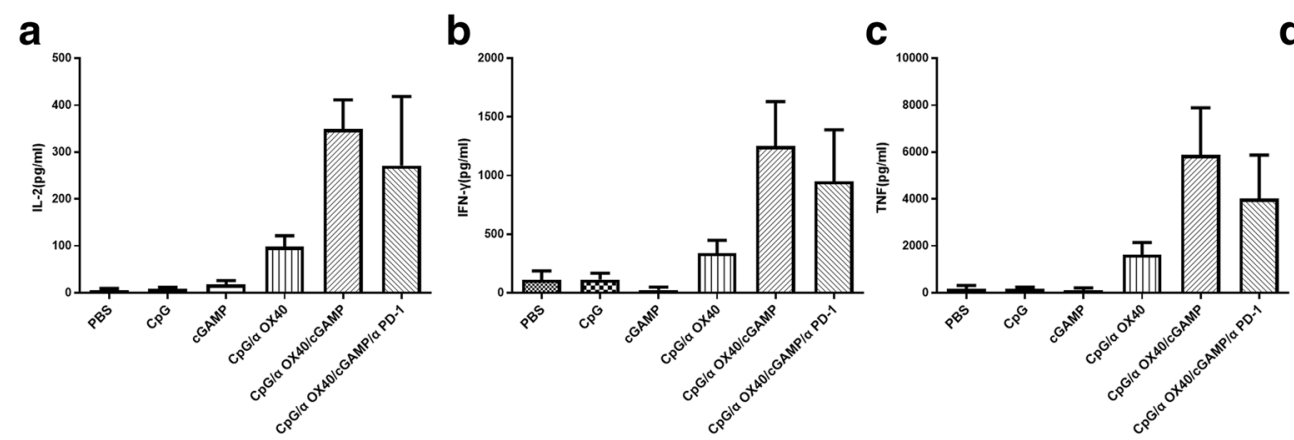

d
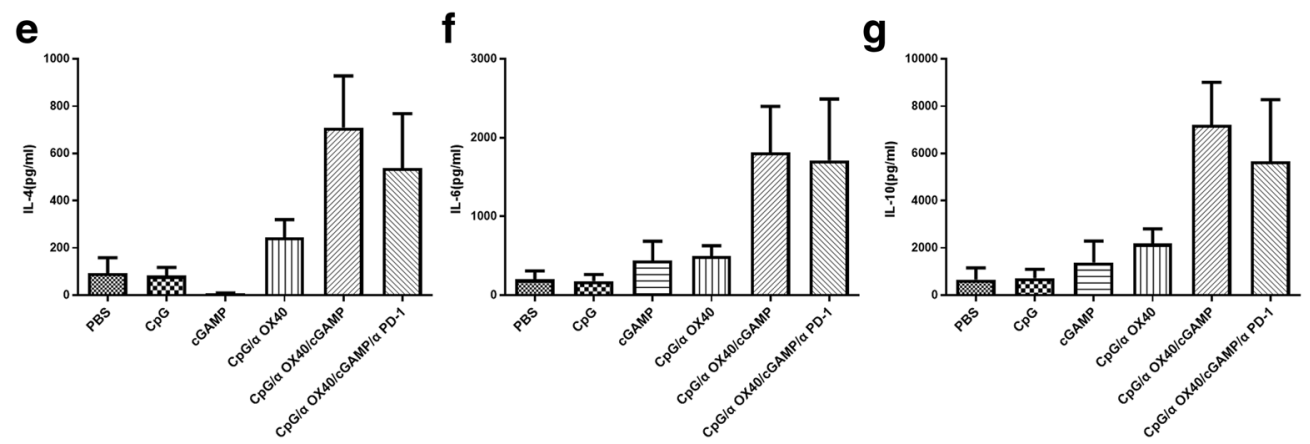

Fig. 6 Triple therapy systematically increases cytokine production in mice. a IL-2, b IFN- $\gamma$, c TNF, d IL-17A, e IL-4, f IL-6 and g IL-10 


\section{The combination of aPD-1 and triple therapy cannot enhance the systematic antitumour effect on aPD-1-resistant cell lines}

Finally, we wondered whether triple therapy combined with $\alpha \mathrm{PD}-1$ would exert a better effect, and thus, we conducted further animal experiments. Interestingly, when combined with $\alpha$ PD- 1 , the systematic antitumour effect of triple therapy was not better but tended to be worse (Fig. 7b), although it did not affect the antitumour efficacy on the treatment side (Fig. 7a). Coincidentally, the serum levels of cytokines were also consistent with this phenomenon, which may partially explain the findings. In this case, the application of the four drugs in combination did not increase the production of cytokines to improve the antitumour effect compared with triple therapy (Fig. 6). Furthermore, we explored combination therapy in the $\alpha \mathrm{PD}-1$-sensitive cell line CT26 and found that the systematic antitumour effect was better than triple therapy: distant tumours grew very slowly (Fig. 7c-d), and even the tumours of some mice subsided completely, achieving long-term survival (Fig. 7e and Supplementary Fig. 2). In terms of experimental safety, we observed the appearance and behavioural characteristics of the mice and recorded the changes in body weight of the mice during the experiment (Fig. 7f). None of the treated mice exhibited side effects such as weight loss, abnormal behaviour or accidental death.

\section{Discussion}

In our study, we designed an effective treatment method for tumours that do not respond to PD-1 immune checkpoint inhibitors. By administering an in situ injection of three drugs in combination, namely the TLR9 agonist CpG, agonistic anti-OX40 antibody and STING agonist cGAMP, we not only significantly slowed the growth of tumours at the injection site but also altered the growth of distant tumours. This treatment even caused the regression of the tumours on the treatment side or on both sides in some mice, showing a strong systemic antitumour effect.

In situ injection of antitumour drugs is a practical strategy for cancer immunotherapy [21,22]; in situ injection of $\mathrm{CpG}$ increases the expression of OX40 on $\mathrm{CD}^{+}{ }^{+} \mathrm{T}$ cells in the tumour microenvironment, and the agonistic antibody OX40 triggers the immune response mediated by $\mathrm{T}$ cells and produces a systemic antitumour effect. Undeniably, $\mathrm{CpG}$ combined with in situ anti-OX40 antibody injection is a good drug combination [12]. However, this combination of drugs is not effective against all tumours. For example, in our study, the therapeutic effect of the in situ injection of $\mathrm{CpG} / \alpha \mathrm{OX} 40$ was not ideal in $\mathrm{TC} 1$ and $\mathrm{B} 16$ tumours, which are $\alpha \mathrm{PD}-1-$-resistant malignancies. Surprisingly, when we combined these drugs with the STING agonist
cGAMP, the antitumour effect was significantly enhanced and is expected to overcome the limitation of $\mathrm{CpG} / \alpha \mathrm{OX} 40$ therapy. Consistent with the results obtained with $\mathrm{CpG} /$ $\alpha \mathrm{OX} 40$ therapy, $\mathrm{CpG} / \alpha \mathrm{OX} 40 / \mathrm{cGAMP}$ therapy also fully mobilized $\mathrm{CD}^{+} \mathrm{T}$ cells. The flow cytometry results showed significantly increased proportions of $\mathrm{CD}^{+}$and $\mathrm{CD} 8^{+} \mathrm{T}$ cells in the spleen, and the infiltration of $\mathrm{CD} 4^{+} \mathrm{T}$ cells was dramatically increased in the distant tumours by approximately threefold compared with that in the control group. After the administration of triple therapy, immune cell infiltration into the distant tumour was dramatically increased, transforming the tumour from the original "cold" tumour to a "hot" tumour $[23,24]$. Although $\mathrm{CD} 8^{+} \mathrm{T}$ cells play an important role in antitumour immunity, $\mathrm{CD} 4^{+} \mathrm{T}$ cells also play an indispensable role. In tumour immunity, $\mathrm{CD} 4^{+} \mathrm{T}$ cells activate $\mathrm{CD} 8^{+} \mathrm{T}$ cells through various mechanisms and promote their differentiation into cytotoxic $\mathrm{T}$ lymphocytes (CTLs) to maintain and strengthen the antitumour response of CTLs. On the other hand, even in the absence of $\mathrm{CD}^{+} \mathrm{T}$ cells, $\mathrm{CD}^{+}{ }^{+} \mathrm{T}$ cells also directly kill tumour cells through an IFN- $\gamma$-dependent mechanism [25-28]. In terms of the therapeutic effect and the proportion of $\mathrm{T}$ cells, $\mathrm{CpG} / \alpha \mathrm{OX} 40 /$ cGAMP therapy is indeed better. Additionally, $\mathrm{CpG} / \alpha \mathrm{OX} 40 /$ cGAMP therapy fully mobilizes innate immunity. In the cell depletion experiment, the systemic antitumour effect of the triple therapy disappeared only when $\mathrm{CD} 4^{+} \mathrm{T}$ cells, $\mathrm{CD} 8^{+} \mathrm{T}$ cells and NK cells were all knocked out, indicating that both adaptive immunity and innate immunity played an essential role. Previous studies have found that an intratumoural injection of $\mathrm{CpG} / \mathrm{cGAMP}$ also induces adaptive immunity and innate immunity, which further confirmed our findings [13].

In addition, triple therapy fully mobilized various cytokines, including Th1, Th2 and Th17 cytokines, which play important roles in regulating innate immunity and adaptive immunity. Th1 cytokines mainly include IL-2, IFN- $\gamma$, TNF and IL-12, which promote the activation and proliferation of cytotoxic $\mathrm{T}$ cells and dominate cellular immunity $[29,30]$. Meanwhile, Th2 cytokines mainly include IL-4, IL-6 and IL-10, which play an important role in humoural immunity by regulating $\mathrm{B}$ cell activity and promoting antibody production [31-33]. Although IL-10 is an immunosuppressive cytokine, several studies have found that IL-10 induces effective antitumour immune surveillance and controls tumour growth [34-36]. In addition, IL-17 is mainly secreted by Th17 cells [37]. IL-17 plays different roles in the development of different tumours and may promote or inhibit tumour growth. Martin-Orozco et al. reported that IL-17 activates tumour-specific $\mathrm{CD} 8^{+} \mathrm{T}$ cells and inhibits the progression of B16-F10 melanoma with lung metastasis [38]. However, according to our current research results, it is difficult to infer the role of IL-10 and IL-17 because although the increase in IL-10 and IL-17 production was accompanied by the activation of antitumour immunity and 

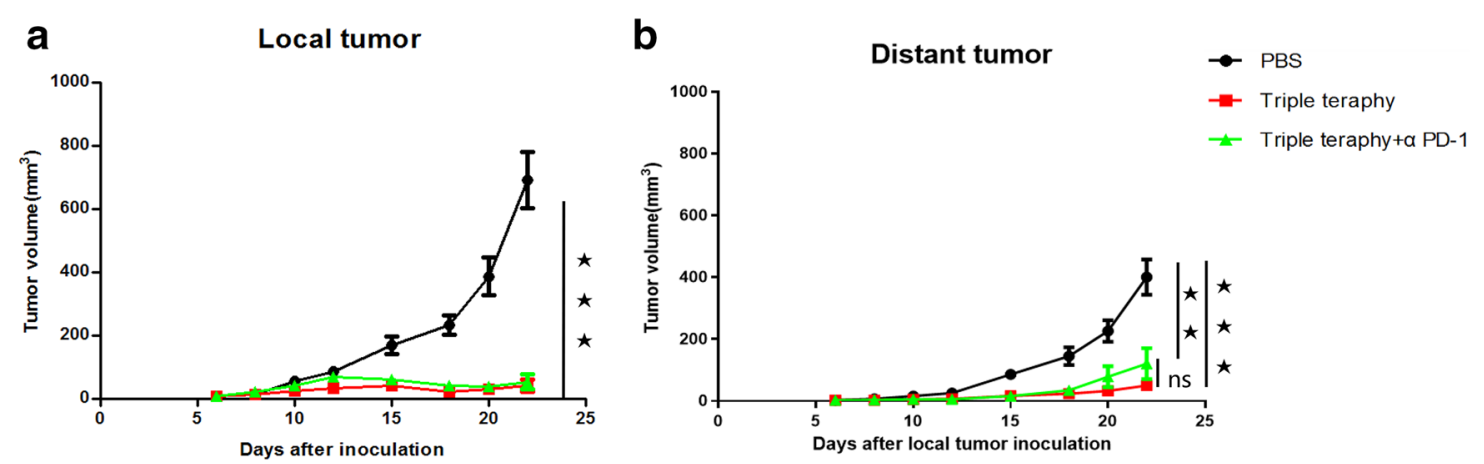

C

d

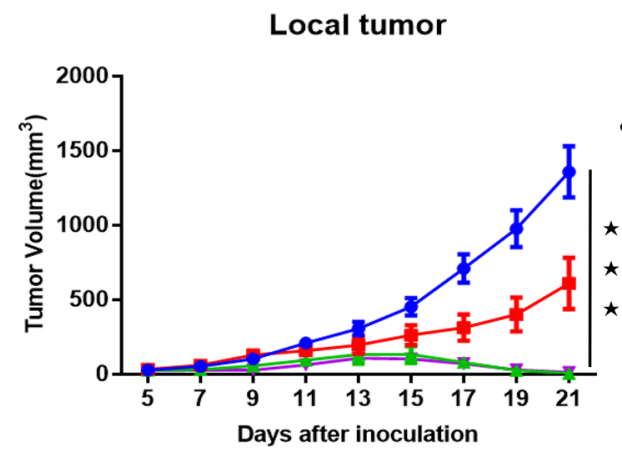

$\star$ *
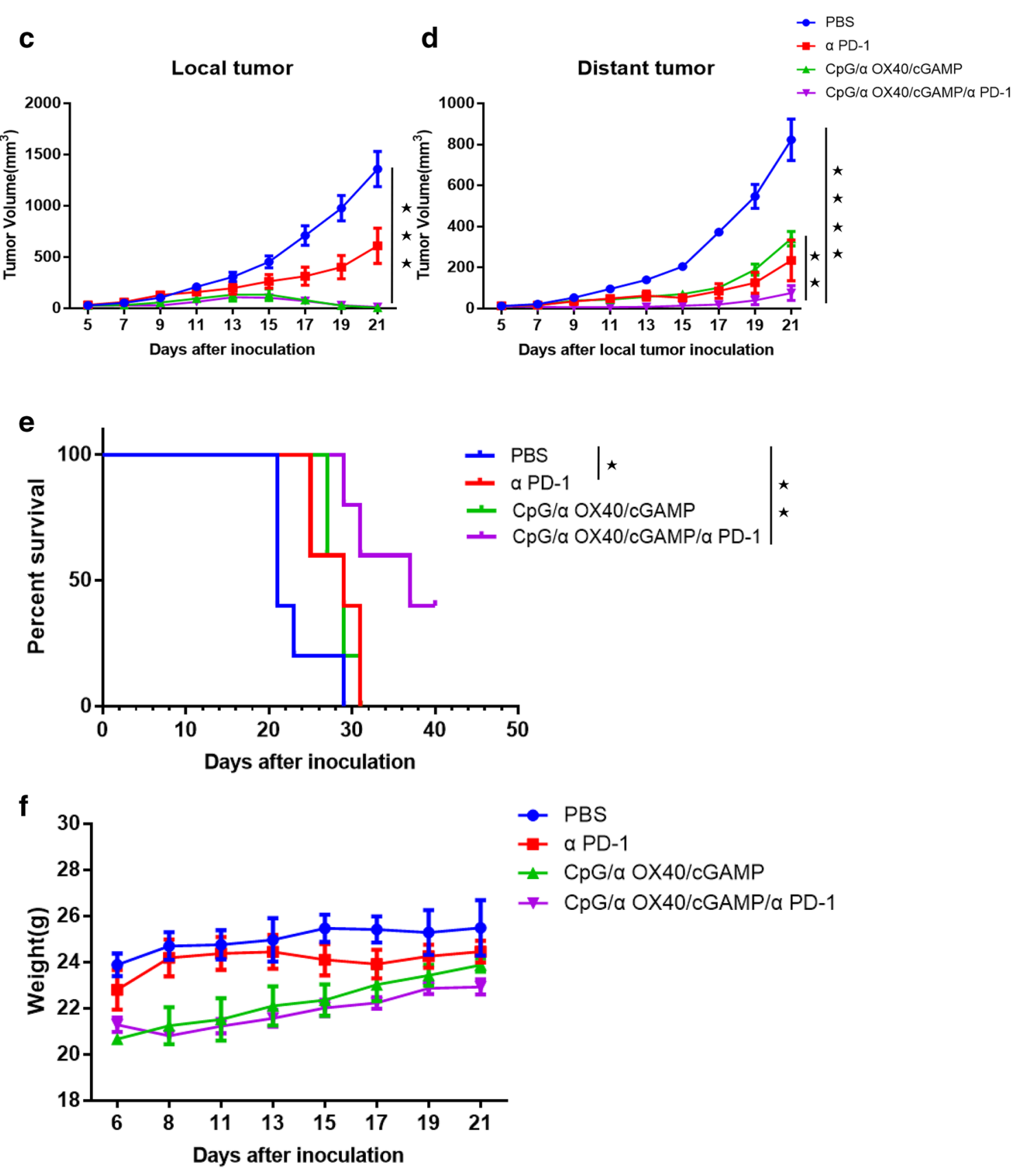
4Fig. 7 The addition of $\alpha$ PD-1 does not enhance the therapeutic efficacy of triple therapy in a TC1 mouse tumour model. The TC1 tumour growth curves for the treated side (a) and untreated side (b) are shown. In the PD-1-sensitive cell line CT26, aPD-1 and triple adjuvant had synergistic therapeutic effects. Tumour growth curves. Local tumour (c); distant tumour (d). e The survival of CT26 tumourbearing mice. $\mathbf{f}$ Changes in the body weight of mice during the experiment

the inhibition of tumour growth, a large number of other immunostimulatory cytokines were also increased. The activation of the OX40-OX40L signalling pathway has been reported to affect different $\mathrm{T}$ cell subsets, such as Th1, Th2 and Th17 cells [39-43]. According to Levy et al., CpG/ $\alpha \mathrm{OX} 40$ therapy increases the expression of the cytokines IL-12, TNF and IFN [12]. Therefore, we speculate that the effect of the agonistic anti-OX40 antibody is fully activated after treatment with the combination of cGAMP with $\mathrm{CpG} /$ $\alpha \mathrm{OX} 40$, which not only enhances the immune response mediated by Th1 cells but also promotes the production of Th2 and Th17 cytokines.

Finally, our study found that a new combination therapy also substantially suppressed the progression of tumours that failed to respond to PD-1 immune checkpoint inhibitors. Currently, two types of tumour immunotherapy are usually used: one is to relieve the inhibitory effect of cancer cells on immune cells by administering drugs, such as $\alpha \mathrm{PD}-1 / \alpha \mathrm{PD}-\mathrm{L} 1$ and $\alpha \mathrm{CTLA}-4$ antibodies, an approach often compared to "releasing the brakes"[44, 45]; the other is to enhance the activity of immune cells to fight cancer by administering drugs, such as the anti-OX40 antibody and anti-41-BB antibody [46], which we often compare to "stepping on the accelerator"[47]. In our study, when the "removing the brakes" approach was ineffective against TC1/B16 cancer cells, we used the "step on the accelerator" approach. Excitingly, in situ injection of $\mathrm{CpG} / \alpha \mathrm{OX} 40 /$ cGAMP showed amazing systemic antitumour efficacy, promoting the secretion of a large number of cytokines and fully activating adaptive and innate immune responses. Furthermore, in $\alpha \mathrm{PD}-1$-resistant cell lines, when we combined $\alpha \mathrm{PD}-1$ with $\mathrm{CpG} / \alpha \mathrm{OX} 40 / \mathrm{cGAMP}$, the antitumour effect was not enhanced but appeared to be worse than that of $\mathrm{CpG} /$ $\alpha \mathrm{OX} 40 / \mathrm{cGAMP}$ alone. This result was also confirmed by the cytokine levels, which did not increase after the administration of the four drugs in combination compared with triple therapy. However, in the $\alpha \mathrm{PD}-1$-sensitive cell line CT26, we found a synergistic effect with this combination. Hence, we hypothesized that following the administration of triple therapy in $\alpha \mathrm{PD}-1$-resistant cell lines, tumour cells may escape the attack of immune cells through other escape mechanisms rather than by expressing the immunosuppressive molecule PD-1, such as the expression of other immunosuppressive molecules CTLA-4 [48] and TIM3 [49, 50], the increased expression of anti-apoptotic molecules [51,
52] or the decreased expression of antigens expressed by tumour cells [53, 54]. Moreover, the PD-1 immune checkpoint inhibitor may exert an opposite effect on shaping the environment created by triple therapy. We have not clearly elucidated the specific mechanism, and further in-depth studies are required.

Compared with other tumour immunotherapies, such as adaptive cell therapy, immune checkpoint inhibitors and tumour vaccines, the in situ injection of $\mathrm{CpG} / \alpha \mathrm{OX} 40 /$ cGAMP triggered an effective antitumour immune response while limiting the risk of systemic exposure and associated toxicity, which not only alters the tumour microenvironment at the injection site but also produces a systemic immune response and suppresses the development of distant tumours. Of course, our research also has some limitations. First, in situ injections are only achieved when the tumour is sufficiently large and accessible, which leads to the practical limitations of tumour treatment. Second, our analysis of the antitumour mechanism of triple therapy was not performed at a sufficient depth, and the reasons why $\alpha \mathrm{PD}-1$ does not enhance the curative effect of $\mathrm{CpG} / \alpha \mathrm{OX} 40 / \mathrm{cGAMP}$ are not clear; therefore, the escape mechanism requires further exploration in future studies.

In summary, we designed an effective and safe drug combination. In situ $\mathrm{CpG} / \alpha \mathrm{OX} 40 / \mathrm{cGAMP}$ injection generates a systemic antitumour immune response and simultaneously activates adaptive and innate immune responses, which is expected to overcome the bottleneck of ineffective treatment with PD-1/PD-L1 immune checkpoint inhibitors and provide benefits to certain cancer patients.

\section{Conclusion}

In general, our study found that in situ vaccination with $\mathrm{CpG} / \alpha \mathrm{OX} 40 / \mathrm{cGAMP}$ can be an effective treatment in a murine model of anti-PD1-resistant tumours. This method can not only activate both adaptive and innate immunity but also fully activate the production of cytokines, including Th1, Th2 and Th17 cytokines, exerting a non-negligible "heating" effect on the tumour immune microenvironment (Fig. 1). We believe that this kind of therapy can revolutionize the treatment of patients exhibiting $\alpha \mathrm{PD}-1$ resistance.

Supplementary Information The online version contains supplementary material available at https://doi.org/10.1007/s00262-021-03095-z.

Author contributions W.F.L., X.P.S. and X.J.Y. designed and supervised the research; L.Y.C., X.D.D., C.Z. and S.S.Y. performed most of the experiments. L.X.L., J.D.Z., Y.Z., C.H.Z., J.T.W. and B.W. analysed and discussed the data.

Funding This work was supported by the National Natural Science Foundation of China (No. 80218103), the Zhejiang Traditional Chinese 
Medicine Administration of China No. 2020ZB144 (XY), the Wenzhou Municipal Science and Technology Bureau of China No. Y20190014 (XY) and the Natural Science Foundation of Zhejiang Province No. Y21H160267 (XY).

Data availability The authors declare that the data supporting the findings of this study are available within the paper and its supplementary information files or available from the corresponding author upon reasonable request. Source data are provided with this paper.

\section{Declarations}

Conflict of interests The authors declare no competing interests.

Ethical approval and consent to participate All animal experimental procedures were conducted in accordance with guidelines for the care and use of laboratory animals from the National Institutes of Health and were approved by the Animal Experimental Ethics Committee of Wenzhou Medical University.

Consent for publication The content of this manuscript has not been previously published and is not under consideration for publication elsewhere.

Open Access This article is licensed under a Creative Commons Attribution 4.0 International License, which permits use, sharing, adaptation, distribution and reproduction in any medium or format, as long as you give appropriate credit to the original author(s) and the source, provide a link to the Creative Commons licence, and indicate if changes were made. The images or other third party material in this article are included in the article's Creative Commons licence, unless indicated otherwise in a credit line to the material. If material is not included in the article's Creative Commons licence and your intended use is not permitted by statutory regulation or exceeds the permitted use, you will need to obtain permission directly from the copyright holder. To view a copy of this licence, visit http://creativecommons.org/licenses/by/4.0/.

\section{References}

1. Bray F, Ferlay J, Soerjomataram I, Siegel RL, Torre LA, Jemal A (2018) Global cancer statistics 2018: GLOBOCAN estimates of incidence and mortality worldwide for 36 cancers in 185 countries. CA Cancer J Clin 68(6):394-424. https://doi.org/10.3322/ caac. 21492

2. Ansell SM, Lesokhin AM, Borrello I, Halwani A, Scott EC, Gutierrez M et al (2015) PD-1 Blockade with Nivolumab in Relapsed or Refractory Hodgkin's Lymphoma. N Engl J Med 372(4):311319. https://doi.org/10.1056/NEJMoa1411087

3. (2015) PD-1 inhibitors effective in hodgkin lymphoma. Cancer Discov 52(2):102-3. https://doi.org/10.1158/2159-8290. CD-NB2015-002.

4. Shanbhag S, Ambinder RF (2018) Hodgkin lymphoma: a review and update on recent progress. CA Cancer J Clin 68(2):116-132. https://doi.org/10.3322/caac.21438

5. (2018) Pembrolizumab Monotherapy for NSCLC Extends Survival. Cancer Discov, https://doi.org/10.1158/2159-8290. CD-NB2018-074.

6. Gettinger S, Rizvi NA, Chow LQ, Borghaei H, Brahmer J, Ready $\mathrm{N}$ et al (2016) Nivolumab monotherapy for first-line treatment of advanced non-small-cell lung cancer. J Clin Oncol 34(25):29802987. https://doi.org/10.1200/jco.2016.66.9929
7. Brahmer J, Reckamp KL, Baas P, Crinò L, Eberhardt WEE, Poddubskaya E et al (2015) Nivolumab versus docetaxel in advanced squamous-cell non-small-cell lung cancer. N Engl J Med 373(2):123-135. https://doi.org/10.1056/NEJMoa1504627

8. Ribas A, Hamid O, Daud A, Hodi FS, Wolchok JD, Kefford R et al (2016) Association of pembrolizumab with tumor response and survival among patients with advanced melanoma. JAMA 315(15):1600. https://doi.org/10.1001/jama.2016.4059

9. Eggermont AMM, Blank CU, Mandala M, Long GV, Atkinson V, Dalle $S$ et al (2018) Adjuvant pembrolizumab versus placebo in resected stage III melanoma. N Engl J Med 378(19):1789-1801. https://doi.org/10.1056/NEJMoa1802357

10. Sullivan RJ, Flaherty KT (2015) Anti-PD-1 therapies-a new first-line option in advanced melanoma. Nat Rev Clin Oncol 12(11):625-626. https://doi.org/10.1038/nrclinonc.2015.170

11. Marabelle A, Tselikas L, de Baere T, Houot R (2017) Intratumoral immunotherapy: using the tumor as the remedy. Ann Oncol, 28: xii33-xii43. https://doi.org/10.1093/annonc/mdx683

12. Sagiv-Barfi I, Czerwinski DK, Levy S, Alam IS, Mayer AT, Gambhir SS et al (2018) Eradication of spontaneous malignancy by local immunotherapy. Science Translational Medicine 10(426):eaan4488. https://doi.org/10.1126/scitranslmed.aan4488

13. Temizoz B, Kuroda E, Ohata K, Jounai N, Ozasa K, Kobiyama $\mathrm{K}$ et al (2015) TLR9 and STING agonists synergistically induce innate and adaptive type-II IFN. Eur J Immunol 45(4):1159-1169. https://doi.org/10.1002/eji.201445132

14. Monjazeb AM, Kent MS, Grossenbacher SK, Mall C, Zamora AE, Mirsoian A et al (2016) Blocking Indolamine-2,3-Dioxygenase rebound immune suppression boosts antitumor effects of radioimmunotherapy in murine models and spontaneous canine malignancies. Clin Cancer Res 22(17):4328-4340. https://doi.org/10. 1158/1078-0432.ccr-15-3026

15. Brody JD, Ai WZ, Czerwinski DK, Torchia JA, Levy M, Advani RH et al (2010) In situ vaccination with a TLR9 agonist induces systemic lymphoma regression: a phase I/II study. J Clin Oncol 28(28):4324-4332. https://doi.org/10.1200/jco.2010.28.9793

16. Kim YH, Gratzinger D, Harrison C, Brody JD, Czerwinski DK, Ai WZ et al (2012) In situ vaccination against mycosis fungoides by intratumoral injection of a TLR9 agonist combined with radiation: a phase 1/2 study. Blood 119(2):355-363. https://doi.org/10.1182/ blood-2011-05-355222

17. Hammerich L, Marron TU, Upadhyay R, Svensson-Arvelund J, Dhainaut M, Hussein S et al (2019) Systemic clinical tumor regressions and potentiation of PD1 blockade with in situ vaccination. Nat Med 25(5):814-824. https://doi.org/10.1038/ s41591-019-0410-x

18. Liu Z, Zhou H, Wang W, Fu Y-X, Zhu M (2016) A novel dendritic cell targeting HPV16 E7 synthetic vaccine in combination with PD-L1 blockade elicits therapeutic antitumor immunity in mice. OncoImmunology 5(6):e1147641. https://doi.org/10.1080/21624 02x.2016.1147641

19. Waaler J, Mygland L, Tveita A, Strand MF, Solberg NT, Olsen PA et al (2020) Tankyrase inhibition sensitizes melanoma to PD-1 immune checkpoint blockade in syngeneic mouse models. Commun Biol. https://doi.org/10.1038/s42003-020-0916-2

20. Zhai W, Zhou X, Zhai M, Li W, Ran Y, Sun Y et al (2020) Blocking of the PD-1/PD-L1 interaction by a novel cyclic peptide inhibitor for cancer immunotherapy. Sci China Life Sci. https://doi.org/ $10.1007 / \mathrm{s} 11427-020-1740-8$

21. Houot R, Levy R (2009) T-cell modulation combined with intratumoral $\mathrm{CpG}$ cures lymphoma in a mouse model without the need for chemotherapy. Blood 113(15):3546-3552. https://doi.org/10. 1182/blood-2008-07-170274

22. Marabelle A, Kohrt H, Sagiv-Barfi I, Ajami B, Axtell RC, Zhou $\mathrm{G}$ et al (2013) Depleting tumor-specific Tregs at a single site 
eradicates disseminated tumors. J Clin Investig 123(6):24472463. https://doi.org/10.1172/jci64859

23. Galon J, Bruni D (2019) Approaches to treat immune hot, altered and cold tumours with combination immunotherapies. Nat Rev Drug Discov 18(3):197-218. https://doi.org/10.1038/ s41573-018-0007-y

24. Duan Q, Zhang H, Zheng J, Zhang L (2020) Turning cold into hot: firing up the tumor microenvironment. Trends Cancer 6(7):605618. https://doi.org/10.1016/j.trecan.2020.02.022

25. Binnewies M, Mujal AM, Pollack JL, Combes AJ, Hardison EA, Barry KC et al (2019) Unleashing Type-2 dendritic cells to drive protective antitumor CD4+ T cell immunity. Cell 177(3):556-71. e16. https://doi.org/10.1016/j.cell.2019.02.005

26. Alspach E, Lussier DM, Miceli AP, Kizhvatov I, DuPage M, Luoma AM et al (2019) MHC-II neoantigens shape tumour immunity and response to immunotherapy. Nature 574(7780):696-701. https://doi.org/10.1038/s41586-019-1671-8

27. Kreiter S, Vormehr M, van de Roemer N, Diken M, Löwer M, Diekmann J et al (2015) Mutant MHC class II epitopes drive therapeutic immune responses to cancer. Nature 520(7549):692-696. https://doi.org/10.1038/nature14426

28. Tran E, Turcotte S, Gros A, Robbins PF, Lu YC, Dudley ME et al (2014) Cancer immunotherapy based on mutation-specific CD4+ T Cells in a patient with epithelial cancer. Science 344(6184):641-645. https://doi.org/10.1126/science.1251102

29. Kim D-H, Park H-J, Lim S, Koo J-H, Lee H-G, Choi JO et al (2018) Regulation of chitinase-3-like-1 in T cell elicits Th1 and cytotoxic responses to inhibit lung metastasis. Nat Commun. https://doi.org/10.1038/s41467-017-02731-6

30. Alam MM, Jarvis CM, Hincapie R, McKay CS, Schimer J, Sanhueza CA et al (2020) Glycan-modified virus-like particles Evoke T helper type 1-like immune responses. ACS Nano. https://doi. org/10.1021/acsnano.0c03023

31. Lan Q (2006) Cytokine polymorphisms in the Th1/Th2 pathway and susceptibility to non-Hodgkin lymphoma. Blood 107(10):4101-4108. https://doi.org/10.1182/blood-2005-10-4160

32. Raphael I, Nalawade S, Eagar TN, Forsthuber TG (2015) T cell subsets and their signature cytokines in autoimmune and inflammatory diseases. Cytokine 74(1):5-17. https://doi.org/10.1016/j. cyto.2014.09.011

33. Walker JA, McKenzie ANJ (2017) TH2 cell development and function. Nat Rev Immunol 18(2):121-133. https://doi.org/10. 1038/nri.2017.118

34. Dennis KL, Saadalla A, Blatner NR, Wang S, Venkateswaran V, Gounari F et al (2015) T-cell expression of IL10 Is essential for tumor immune surveillance in the small intestine. Cancer Immunol Res 3(7):806-814. https://doi.org/10.1158/2326-6066. cir-14-0169

35. Oft M (2019) Immune regulation and cytotoxic $\mathrm{T}$ cell activation of IL-10 agonists - Preclinical and clinical experience. Semin Immunol 44:101325. https://doi.org/10.1016/j.smim.2019.101325

36. Mumm John B, Emmerich J, Zhang X, Chan I, Wu L, Mauze S et al (2011) IL-10 Elicits IFN $\gamma$-Dependent Tumor Immune Surveillance. Cancer Cell 20(6):781-796. https://doi.org/10.1016/j. ccr.2011.11.003

37. Iwakura Y, Ishigame H, Saijo S, Nakae S (2011) Functional specialization of Interleukin-17 family members. Immunity 34(2):149-162. https://doi.org/10.1016/j.immuni.2011.02.012

38. Martin-Orozco N, Muranski P, Chung Y, Yang XO, Yamazaki $\mathrm{T}, \mathrm{Lu} \mathrm{S}$ et al (2009) T Helper 17 cells promote Cytotoxic T cell activation in tumor immunity. Immunity 31(5):787-798. https:// doi.org/10.1016/j.immuni.2009.09.014
39. Fu Y, Lin Q, Zhang Z, Zhang L (2020) Therapeutic strategies for the costimulatory molecule OX40 in T-cell-mediated immunity. Acta Pharmaceutica Sinica B 10(3):414-433. https://doi.org/10. 1016/j.apsb.2019.08.010

40. Croft M (2010) Control of immunity by the TNFR-related molecule OX40 (CD134). Annu Rev Immunol 28(1):57-78. https:// doi.org/10.1146/annurev-immunol-030409-101243

41. Lane P (2000) Role of OX40 signals in coordinating CD4 T cell selection, migration, and cytokine differentiation in $\mathrm{T}$ helper (Th)1 and Th2 cells. J Exp Med 191(2):201-206. https://doi.org/ 10.1084/jem.191.2.201

42. Gramaglia I, Jember A, Pippig SD, Weinberg AD, Killeen N, Croft M (2000) The OX40 costimulatory receptor determines the development of CD4 memory by regulating primary clonal expansion. J Immunol 165(6):3043-3050. https://doi.org/10.4049/ jimmunol.165.6.3043

43. Murata K, Nose M, Ndhlovu LC, Sato T, Sugamura K, Ishii N (2002) Constitutive OX40/OX40 ligand interaction induces autoimmune-like diseases. J Immunol 169(8):4628-4636. https://doi. org/10.4049/jimmunol.169.8.4628

44. Weigmann K. (2016) Releasing the brakes to fight cancer. EMBO Rep 17(9):1257-60. https://doi.org/10.15252/embr.201643038.

45. Le Mercier I, Lines JL, Noelle RJ (2015) Beyond CTLA-4 and PD-1, the Generation Z of Negative Checkpoint Regulators. Front Immunol. https://doi.org/10.3389/fimmu.2015.00418

46. Chester C, Ambulkar S, Kohrt HE (2016) 4-1BB agonism: adding the accelerator to cancer immunotherapy. Cancer Immunol Immunother 65(10):1243-1248. https://doi.org/10.1007/ s00262-016-1829-2

47. DA Knorr DR, Ravetch JV (2018) Toxicity of an Fc-engineered anti-CD40 antibody is abrogated by intratumoral injection and results in durable antitumor immunity. Proc Natl Acad Sci U S A 115(43):11048-11053. https://doi.org/10.1073/pnas.1810566115

48. Leach DR, Krummel MF, Allison JP (1996) Enhancement of antitumor immunity by CTLA-4 blockade. Science 271(5256):17341736. https://doi.org/10.1126/science.271.5256.1734

49. Wolf Y, Anderson AC, Kuchroo VK (2019) TIM3 comes of age as an inhibitory receptor. Nat Rev Immunol 20(3):173-185. https:// doi.org/10.1038/s41577-019-0224-6

50. Alderton GK (2012) TIM3 suppresses antitumour DCs. Nat Rev Cancer 12(9):584. https://doi.org/10.1038/nrc3349

51. Yang F, Wei Y, Cai Z, Yu L, Jiang L, Zhang C et al (2014) Activated cytotoxic lymphocytes promote tumor progression by increasing the ability of 3LL tumor cells to mediate MDSC chemoattraction via Fas signaling. Cell Mol Immunol 12(1):66-76. https://doi.org/10.1038/cmi.2014.21

52. Ibrahim R, Frederickson H, Parr A, Ward Y, Moncur J, Khleif SN (2006) Expression of FasL in squamous cell carcinomas of the cervix and cervical intraepithelial neoplasia and its role in tumor escape mechanism. Cancer 106(5):1065-1077. https://doi.org/10. $1002 /$ cncr.21697

53. Rosenthal R, Cadieux EL, Salgado R, Bakir MA, Moore DA, Hiley CT et al (2019) Neoantigen-directed immune escape in lung cancer evolution. Nature 567(7749):479-485. https://doi.org/10. 1038/s41586-019-1032-7

54. Hamieh M, Dobrin A, Cabriolu A, van der Stegen SJC, Giavridis T, Mansilla-Soto J et al (2019) CAR T cell trogocytosis and cooperative killing regulate tumour antigen escape. Nature 568(7750):112-116. https://doi.org/10.1038/s41586-019-1054-1

Publisher's Note Springer Nature remains neutral with regard to jurisdictional claims in published maps and institutional affiliations. 